\title{
The effect of argon plasma treatment on the permeation barrier properties of silicon nitride layers
}

\author{
S. Majee ${ }^{\text {a,* }}$, M.F. Cerqueira ${ }^{\text {b }}$, D. Tondelier ${ }^{\text {a }}$, B. Geffroy ${ }^{\text {a,c }}$, Y. Bonnassieux ${ }^{\text {a }}$, P. Alpuim ${ }^{\text {b,d }}$, J.E. Bourée ${ }^{\text {a }}$ \\ a Laboratoire de Physique des Interfaces et des Couches Minces, Ecole Polytechnique, CNRS UMR 7647, 91128 Palaiseau, France \\ b Centro de Física, Universidade do Minho, 4710-057 Braga, Portugal \\ c Laboratoire de Chimie des Surfaces et Interfaces, IRAMIS/SPCSI CEA Saclay, 91191 Gif-sur-Yvette, France \\ d INL - International Iberian Nanotechnology Laboratory, 4715-330 Braga, Portugal
}

\section{A R T I C L E I N F O}

Article history:

Received 24 May 2013

Accepted in revised form 27 July 2013

Available online 3 August 2013

\section{Keywords:}

Silicon nitride

Ar plasma treatment

Permeation barrier

HW-CVD

\begin{abstract}
A B S T R A C T
In this work we produce and study silicon nitride $\left(\mathrm{SiN}_{\mathrm{x}}\right)$ thin films deposited by Hot Wire Chemical Vapor Deposition (HW-CVD) to be used as encapsulation barriers for flexible organic photovoltaic cells fabricated on polyethylene terephthalate (PET) substrates in order to increase their shelf lifetime. We report on the results of $\mathrm{SiN}_{\mathrm{x}}$ double-layers and on the equivalent double-layer stack where an Ar-plasma surface treatment was performed on the first $\mathrm{SiN}_{\mathrm{x}}$ layer. The Ar-plasma treatment may under certain conditions influences the structure of the interface between the two subsequent layers and thus the barrier properties of the whole system. We focus our attention on the effect of plasma treatment time on the final barrier properties. We assess the encapsulation barrier properties of these layers, using the calcium degradation test where changes in the electrical conductance of encapsulated Ca sensors are monitored with time. The water vapor transmission rate (WVTR) is found to be $\sim 3 \times 10^{-3} \mathrm{~g} / \mathrm{m}^{2}$. day for stacked $\mathrm{SiN}_{\mathrm{x}}$ double-layer with $8 \mathrm{~min}$ Ar plasma surface treatment.
\end{abstract}

(c) 2013 Elsevier B.V. All rights reserved.

\section{Introduction}

Permeation of oxygen and water vapor into the active layers of organic electronic devices can lead to a serious deterioration of their performance. Permeation is therefore a serious problem for devices made on flexible plastic substrates which, unlike glass, have poor barrier properties. Thus for many devices such as organic light emitting diodes, organic solar cells and flexible displays that can be rolled up, the permeation barrier layers are absolutely necessary. The thin layers of transparent materials such as silica, silicon nitride or alumina which have high intrinsic impermeability are often used as barrier layers. Single layers of these materials often have pinholes through which water molecules (which are more reactive than oxygen molecules) can diffuse up to the organic device surface and thus deteriorate the device [1-3]. Due to that reason, more and more researches have been focused on minimizing the number and size of defects in a single layer or minimizing the propagation of defects by developing a multilayer stack [4]. Recently, almost defect-free layers were successfully deposited using the Atomic Layer Deposition (ALD) technique $[5,6]$. However, on the one hand this technique is extremely slow in terms of deposition rate; on the other hand the number of materials that can be deposited is limited [7]. An effective approach recently reported [7-11] is to deposit multilayers of organic/inorganic films because organic layers can absorb the stresses generated at the interface with hard layers when the devices

\footnotetext{
* Corresponding author. Tel.: +3316933 43 76; fax: + 33169334333 .

E-mail address: subimal.majee@polytechnique.edu (S. Majee).
}

are bent. This route seems particularly interesting if one is able to deposit both the organic and inorganic layers in the same reactor, which is not our case. We opted for the double-layer deposition of inorganic films (silicon nitride) using the Hot Wire Chemical Vapor Deposition (HWCVD) method with a substrate temperature of $100^{\circ} \mathrm{C}$, to be compatible with the use of organic layers or flexible polymeric substrates (polyethylene terephthalate, PET) [12]. This deposition technique was chosen because, in comparison with the conventional plasma assisted CVD (PECVD) technique, the hydrogen concentration in the deposited layers is lower and conformal coverage is better [13]. Other advantages mainly result from the absence of ion bombardment during film growth, combined with a high efficiency of pyrocatalytic decomposition of the source gases, $\mathrm{NH}_{3}$ and $\mathrm{SiH}_{4}$, on the filament surface. Moreover instead of alternating hard layers (inorganic) and flexible layers (organic) we focused on the inorganic/inorganic interfaces and utilized an Ar plasma surface treatment after deposition of each $\mathrm{SiN}_{\mathrm{x}}$ layer [14].

For the commercial use of organic devices fabricated on plastic substrates (PET), there is a wide range of permeation requirements depending on the used materials and final applications. Some recent studies demonstrate that the encapsulation of organic photovoltaic cells with barrier materials corresponding to a water vapor transmission rate (WVTR) in the range between $10^{-4}$ to $10^{-3} \mathrm{~g} / \mathrm{m}^{2}$. day (amount of water molecules diffusing through a unit area of the barrier film per unit time under conditions of the test) is sufficient to achieve lifetimes of several thousands of hours in operation $[11,15,16]$. The main characteristics required for the permeation barrier films are their high density, defect-freeness, good adhesion, thermal stability and uniform thickness. 
Moreover, high electrical resistivity, high transparency in the visible region, low residual stress and the ability to be deposited at low temperature are required for these thin-film materials [4].

The objective of this work is to study the barrier properties of thin $\mathrm{SiN}_{\mathrm{x}}$ single-layer thin-films deposited by HW-CVD, either directly stacked on top of each other or piled up with an argon plasma surface treatment realized between two successive single-layers. In this work we have studied double-layers of $\mathrm{SiN}_{\mathrm{x}}$ thin-films with and without $\mathrm{Ar}$ plasma surface treatment. The idea behind the use of the argon plasma surface treatment between two successive $\mathrm{SiN}_{\mathrm{x}}$ single-layers is to make a break of the propagation of the pinholes from one single-layer to the other. In effect the plasma treatment makes an atomic rearrangement at the interface level [14], which increases the effective diffusion time ("lag-time" defined as the time required for the permeate to diffuse through the whole thickness of the barrier layer [16-18]) of the water molecules toward the organic device surface. We measure the WVTR values for $\mathrm{SiN}_{\mathrm{x}}$ double-layers stacked on PET substrates, with and without argon plasma surface treatment and compare these values with WVTR values measured on uncoated PET substrates. The effect of high-frequency (13.56 MHz) Ar-plasma surface treatment on the WVTR of $\mathrm{SiN}_{\mathrm{x}}$ double-layers is studied as a function of Ar plasma treatment times.

\section{Experimental details}

For HW-CVD a single coil shaped tantalum filament (diameter $=$ $0.5 \mathrm{~mm}$, length $=15 \mathrm{~cm}$ ) is heated up to $2000{ }^{\circ} \mathrm{C}$ with a filament to substrate distance fixed at $7.5 \mathrm{~cm}$. The filament is first heated up to the working temperature, in a hydrogen atmosphere, and then the source gases, $\mathrm{NH}_{3}$ and $\mathrm{SiH}_{4}$, are added. The working pressure is 25 mTorr for all $\mathrm{SiN}_{\mathrm{x}}$ depositions. During the heating time, a shutter is moved to the closed position in order to protect the substrate from the spurious species emitted from the filament. The substrate temperature $\left(T_{\text {sub }}\right)$ is fixed at $100{ }^{\circ} \mathrm{C}$ in order to be compatible with the plastic substrates. The substrate temperature is measured with a thermocouple embedded in a stainless steel substrate-holder, close to the substrate. This means that, especially for the depositions made nominally at $100{ }^{\circ} \mathrm{C}$, the temperature of the film growing surface is certainly higher than the substrate-holder temperature due to the heating from the hot filament [12].

$\mathrm{SiN}_{\mathrm{x}}$ single-layer films are optimized for their optical transmittance $(T)$, refractive index $(n)$ and deposition rate $\left(r_{d}\right)$, in this order. We targeted highly transparent films in the visible and near infra-red region (transmittance $>80 \%$ ) which are simultaneously dense $(n \sim 2)$ and obtainable at a deposition rate, $r_{d}$, as high as possible. Highly transparent films are required for window layers in photovoltaic cells. A refractive index ( $n$ ) of 2 means that the $\operatorname{SiN}_{\mathrm{x}}$ films are dense and close to stoichiometry (as opposed to porous films which have lower $n$, and Si-rich films which have higher $n$ but are not fully transparent). A high $r_{d}$ is important for economic reasons in general and in this case in also avoiding long exposure of the plastic substrate facing the heated filament. Singlelayers and double-layers of $\mathrm{SiN}_{\mathrm{x}}$ thin films are obtained using optimized deposition conditions of $90 \%$ hydrogen dilution of silane and ammonia gaseous mixtures (here hydrogen dilution is defined as the ratio of hydrogen flow to the total gas flow) where the flow rates of hydrogen, ammonia and silane have been fixed at $54 \mathrm{sccm}, 4 \mathrm{sccm}$ and $2 \mathrm{sccm}$ respectively; Ta filament current of $16 \mathrm{~A}$, corresponding to a filament temperature of $2000{ }^{\circ} \mathrm{C}$, which give films with transmittance, in the visible range, higher than $80 \%, n \sim 2(n=2.01$ at $632.8 \mathrm{~nm})$ and $r_{d}=1.4 \AA / \mathrm{s}$. Due to the increase of the substrate temperature with time caused by the heated filament, the single-layer thickness was limited to $50 \mathrm{~nm}$, which corresponds to $360 \mathrm{~s}$ of growth time, under the above described conditions. We note here that, compared to our previous work [12], the substrate-to-filament distance is now increased to $7.5 \mathrm{~cm}$, in order to avoid excessive heating of the PET substrates which have a maximum working temperature of $\sim 110{ }^{\circ} \mathrm{C}$. Under these conditions we find that lowering the working pressure from 40 mTorr to 25 mTorr and using $\mathrm{H}_{2}$ dilution of the reactant gases yields more dense and transparent films than could be obtained by using the optimized deposition parameters for the previous conditions where $\mathrm{H}_{2}$ was not added [12].

In this study, we focused our attention on the surface compaction of the $\mathrm{SiN}_{\mathrm{x}}$ single-layers by using $\mathrm{Ar}$ plasma surface treatment. The $\mathrm{Ar}$ plasma treatment between successive $\mathrm{SiN}_{\mathrm{x}}$ single-layers is carried out in a glow discharge chamber, where the sample is clamped to the top electrode and heated up to $100{ }^{\circ} \mathrm{C}$ and the bottom electrode is the rfpowered electrode. The sequence of $\mathrm{SiN}_{\mathrm{x}}$ deposition and Ar treatment is performed without breaking the vacuum. This is achieved by moving the sample between two twin chambers connected by a gate valve.

The Ar treatment is performed at a working pressure of $50 \mathrm{mTorr}$ and a power density of $350 \mathrm{~mW} / \mathrm{cm}^{2}$ using a $13.56 \mathrm{MHz}$ rf-generator. The plasma treatment time is also varied $(2,5,8,10$ and $15 \mathrm{~min})$ in order to study its effect on the WVTR of the corresponding barrier structures. In this work we study the properties of $\mathrm{SiN}_{\mathrm{x}}$ based-encapsulation systems consisting of two $\mathrm{SiN}_{\mathrm{x}}$ single-layers (total thickness: $2 \times 50 \mathrm{~nm}$ ) either directly deposited one after the other or separated by an Ar plasma treatment performed during 2, 5, 8, 10 and 15 min.

The optical characterization of the layers is performed using the films grown on crystalline silicon wafers at the same substrate temperature $\left(100{ }^{\circ} \mathrm{C}\right)$. The thickness of the single-layer film and the refractive index $(n)$, are assessed by fitting the measured data of the UVISEL HORIBA Jobin Yvon spectroscopic ellipsometer measurements using the DeltaPsi2 fitting software tool. The dispersion relation for the dielectric constant used in the parameterization from which the film's optical constants are obtained, is based on the classical Lorentz dielectric function $\varepsilon(E)$ :

$$
\varepsilon(E)=\varepsilon_{\infty}+\frac{f E_{0}^{2}}{E_{0}^{2}-E^{2}+i \gamma_{b} E}
$$

where $\varepsilon_{\infty}$ is the high frequency dielectric constant, $E_{0}, \gamma_{b}$ and $f$ are, respectively, the resonance energy frequency, the line-width and the strength of the Lorentzian oscillator, related to the bound electrons.

The reflectance $(R)$ and the transmittance $(T)$ curves are measured using PerkinElmer Integrating Sphere on samples grown on PET substrate. The film characterizations are undertaken using the X-ray diffraction (XRD) and analysed with the system software. The surface roughness of the $\mathrm{SiN}_{\mathrm{x}}$ single-layers as well as single-layers separated by Ar plasma surface treatments is measured using atomic force microscopy (AFM) technique.

To measure the water vapor transmission rate (WVTR) value, we use the electrical calcium degradation test [18-20] method implemented inside a glove box flushed with permanent nitrogen with less than $0.1 \mathrm{ppm}$ of oxygen and water vapor. For the Ca degradation test, $100 \mathrm{~nm}$ Ca layer with an area of $1.13 \mathrm{~cm}^{2}$ and aluminium contacts are deposited by thermal evaporation through shadow masks on the back side of the barrier coated PET substrates. The barrier coated substrates are degassed at $90{ }^{\circ} \mathrm{C}$ for about $6 \mathrm{~h}$ inside the glove-box prior to the Ca deposition. A low deposition rate of $0.2 \mathrm{~nm} / \mathrm{s}$ (measured by using a calibrated quartz crystal microbalance near the substrate) and at a pressure of $<10^{-6}$ mbar is chosen to get a really smooth layer for both calcium and aluminium deposition. The $\mathrm{Ca}$ layer plus part of the $\mathrm{Al}$ contacts are then covered with a glass plate and the edges of which are sealed with epoxy resin (Nagase Chemtex Corp. XNR 5570). The resin is cured under a UV-lamp ( $365 \mathrm{~nm}$ wavelength) inside the glove-box. In order to check our sealing performance, the calcium test is also performed on a glass substrate (glass-glass sample). Therefore, the Ca layer is on one side of the barrier film and the other side is exposed to the environment (see Fig. 1). The calcium degradation test is performed under an ambient environmental condition. Water molecules in the environmental moisture after diffusing through the pinholes and defects inside the barrier, reach the calcium sensor and react with the sensor to form $\mathrm{Ca}(\mathrm{OH})_{2}$ and thus reduce its conductivity. 


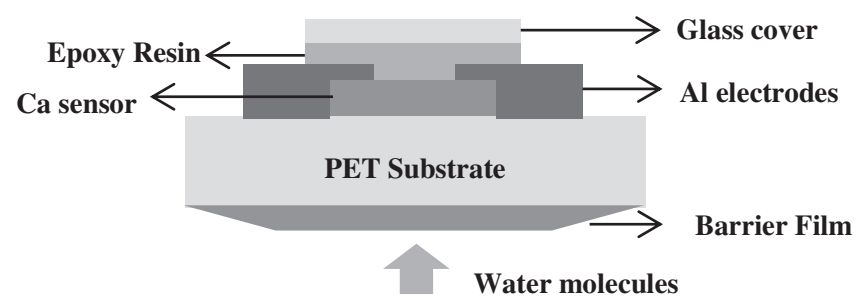

Fig. 1. Schematic side view of electrical calcium degradation test setup (dimensions are not to the scale).

The change of conductance is measured using a four point probe technique of Solartron-Schlumberger 7060 Systems Voltmeter. From this evolution curve lag-time of diffusion and the permeation rate are derived. The WVTR value is deduced from the average slope of the evolution of conductance $(\mathrm{d} G / \mathrm{d} t)$ using the following relation $[19,20]$, which relates the changes in conductance of the Ca layer with a decrease of its thickness caused by reaction with water molecules:

WVTR $=-N \cdot \delta_{C a} \cdot \rho_{C a} \cdot \frac{M(\text { water })}{M(\mathrm{Ca})} \cdot \frac{l}{w} \cdot \frac{d G}{d t} \cdot \frac{\text { Area }(\mathrm{Ca})}{\text { Area }(\text { window })}$

where $N$ is the molar equivalent of the degradation reaction which is assumed as $N=2$ from the chemical reaction of $\mathrm{Ca}$ with water $\left[\mathrm{Ca}+2 \mathrm{H}_{2} \mathrm{O} \rightarrow \mathrm{Ca}(\mathrm{OH})_{2}+\mathrm{H}_{2}\right], M$ is the molar mass of the reactive elements, $\delta_{C a}$ is the density of calcium $\left(1.55 \mathrm{~g} / \mathrm{cm}^{3}\right), \rho_{C a}$ is the calcium resistivity $\left(9 \times 10^{-8} \Omega \cdot \mathrm{m}\right.$ which is in good agreement with ref. [19]), $l$ and $w$ are the effective length and width of Ca layer respectively and $G$ is the conductance. From the geometry of our setup, the value of Area (Ca)/Area (window) is taken to be in unity.

\section{Results and discussion}

Fig. 2 shows the reflectance $(R)$ and the transmittance $(T)$ spectra of the bare PET substrate and double-layer of $\mathrm{SiN}_{\mathrm{x}}$ films on PET substrate. The $T$ and $R$ curves indicate almost no $\mathrm{SiN}_{\mathrm{x}}$ effect and also that the double-layer structure is highly transparent $(>80 \%)$ in the visible region. It can also be seen from the spectra that reflectance and transmittance of this double-layer structure together are around 100\%, meaning that no absorption takes place in the layers and the barrier structure can perfectly be used as a window layer for organic photovoltaic cells. The slight absorption below $450 \mathrm{~nm}$ is due to the PET substrate itself.

From the fit of the spectroscopic ellipsometric measured data to the model, in the visible region, we obtained the refractive index, $n$ and the

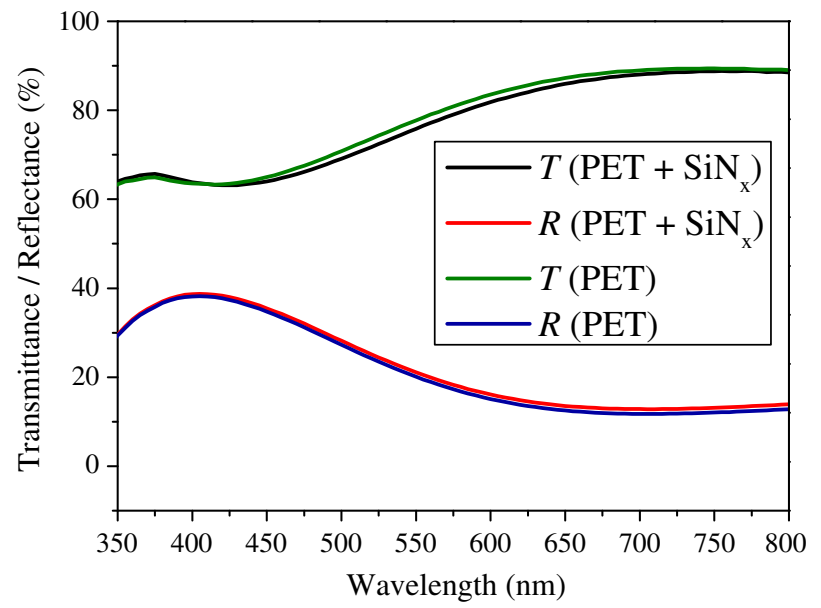

Fig. 2. Reflection and transmission spectra of $\operatorname{SiN}_{\mathrm{x}}$ double-layer on PET substrate. The reflectance $(R)$ and transmittance $(T)$ of the layer together is almost $100 \%$, means no absorption inside the films. extinction coefficient, $k$, shown in Fig. 3. The value of $n$ at $632.8 \mathrm{~nm}$ is 2.01 which is close to the value 2.05 found in the literature for stoichiometric amorphous $\mathrm{Si}_{3} \mathrm{~N}_{4}$ [21-25].

X-ray diffraction patterns of $\mathrm{SiN}_{\mathrm{x}}$ single-layer films deposited on the c-Si substrate and PET foils are shown in Fig. 4. The peaks in those figures are corresponding to the substrates themselves and there is no evidence of crystalline peaks corresponding to the $\mathrm{SiN}_{\mathrm{x}}$ films. It suggested, as expected, that the $\mathrm{SiN}_{\mathrm{x}}$ films deposited at low temperature $\left(100{ }^{\circ} \mathrm{C}\right)$ are amorphous.

The surface modification induced by argon plasma is mainly due to the kinetic energy transfer between $\mathrm{Ar}^{+}$ions and surface atoms of the $\mathrm{SiN}_{\mathrm{x}}$ thin-film during the inelastic collisions. These collisions will lead to two major effects, depending on the ion kinetic energy [26,27]: either at low energy $(<100 \mathrm{eV})$ surface densification by the relocation of atoms deeper below the surface or for high ion energies $(>100 \mathrm{eV})$ surface sputtering with the ejection of atoms out of the film. The argon ion bombardment on the surface must be such that it disrupts the atomic distribution to a few $\mathrm{nm}$ in depth, disturbing the continuity of a structural defect through this interface but it cannot significantly damage the surface. For the conditions used in this work, the argon ion energy after being accelerated through the plasma sheath potential is $<100 \mathrm{eV}$. The bombardment by argon ions with this energy will promote the $\mathrm{SiN}_{\mathrm{x}}$ single-layer densification to a few $\mathrm{nm}$ in depth, probably reducing the pinholes or defects inside the films. It should logically enhance the diffusion barrier properties of $\mathrm{SiN}_{\mathrm{x}} / \mathrm{SiN}_{\mathrm{x}}$ interfaces. Fig. 5 shows the three dimensional surface images and Fig. 6 shows evolution of the average roughness of the sample surface, obtained by atomic force microscopy, of the $\mathrm{SiN}_{\mathrm{x}}$ double-layer without Ar plasma treatment and several double-layers separated by Ar-plasma surface treatment with increased plasma treatment time. The initial roughness of the PET foil before being exposed to the HW-CVD process is $1.35 \mathrm{~nm}$. The roughness of the PET increases strongly when the PET foil is exposed to the Ta filament, probably due to the fact that the glass transition of PET starts at around $80{ }^{\circ} \mathrm{C}$. It is clear from Fig. 6 that for the longer Ar treatment time, the roughness slightly decreases as compared to the untreated films, corresponding to a smoothening of the surface, which is coherent with the densification of the film surface.

Fig. 7 shows the evolution of normalized conductances of Ca sensors, deposited on the produced barrier coated PET substrates with the variation of the plasma treatment duration. In Fig. 7, bare PET and glass substrates are used as references for the calcium degradation test. The degradation test is performed on 10 uncoated PET substrates (Melinex ST $504,175 \mu \mathrm{m}$ thick) to evaluate its reproducibility, as also on glass substrate for proving the limit of our set-up. The WVTR value assessed from the conductance evolution curve shows that the uncoated PET substrate has a WVTR of $0.14 \pm 0.04 \mathrm{~g} / \mathrm{m}^{2}$. day, whereas the glass

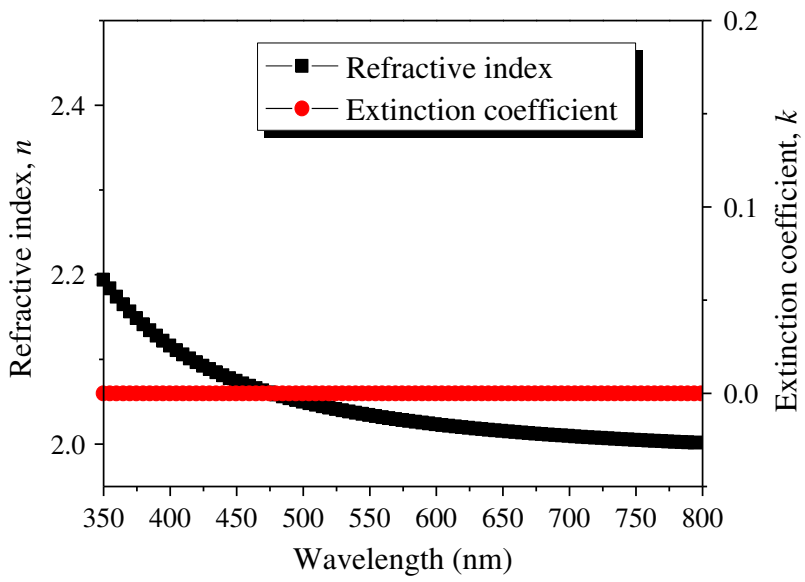

Fig. 3. Refractive index $(n)$ and extinction coefficient $(k)$, in the visible region, obtained from the ellipsometric measurement data for the single-layer of $\mathrm{SiN}_{\mathrm{x}}(50 \mathrm{~nm})$ on c-Si substrate. 


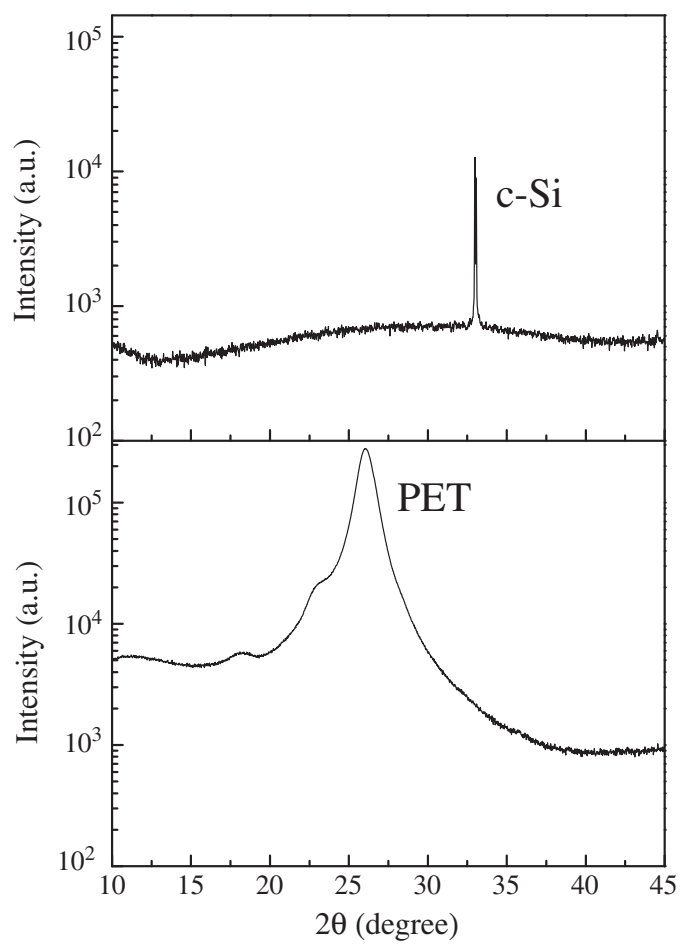

Fig. 4. X-ray diffraction patterns of $\mathrm{SiN}_{\mathrm{x}}$ single-layer films deposited on c-Si substrate and on PET foil.

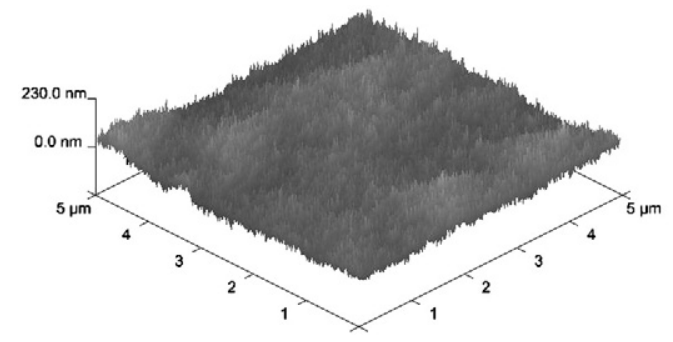

(a)

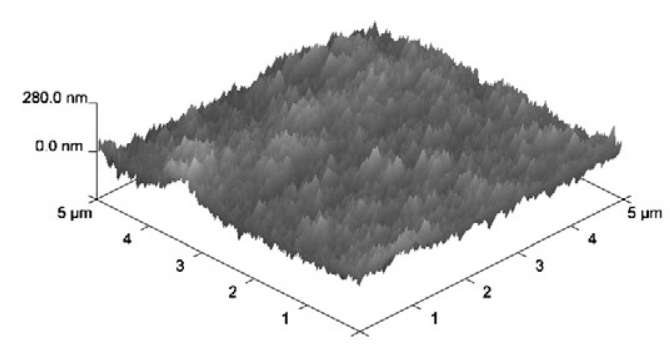

(c)

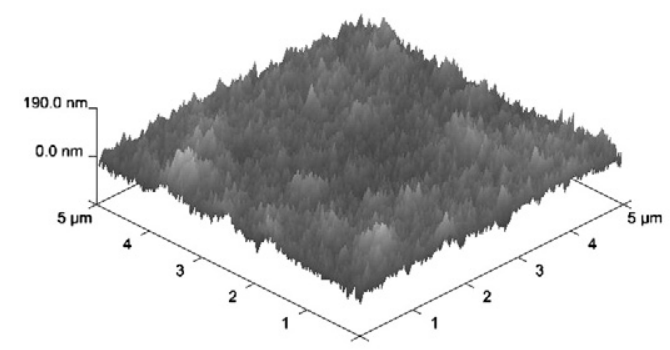

(e)

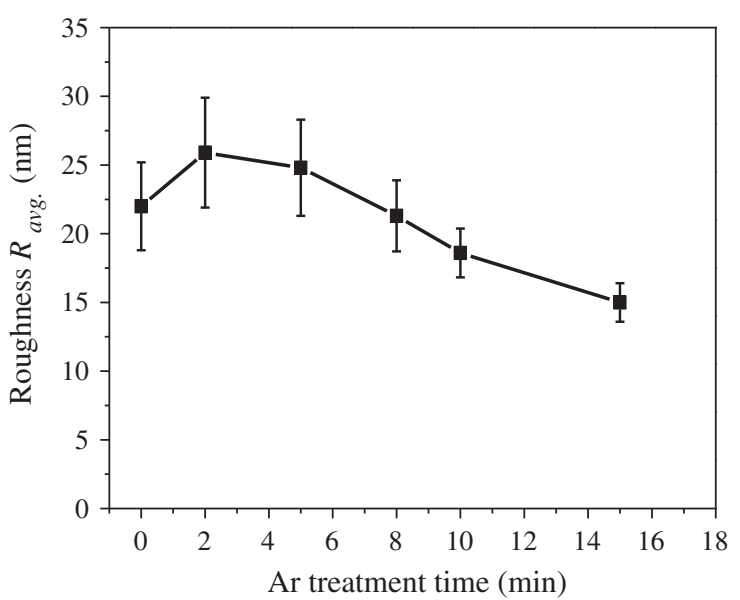

Fig. 6. Average surface roughness of $\mathrm{SiN}_{\mathrm{x}}$ double-layers deposited on PET substrates as a function of the Ar plasma surface treatment time.

substrate shows an estimated WVTR of $\sim 10^{-6} \mathrm{~g} / \mathrm{m}^{2}$ · day. From Fig. 8 we see that the "lag-time" of diffusion [16-18] is increasing with the increase of plasma treatment time and is always higher than that of the double-layer without any plasma treatment. The evolution of the WVTR values for $\mathrm{SiN}_{\mathrm{x}}$ double-layers ( $50 \mathrm{~nm}+50 \mathrm{~nm}$ ) with and without Ar plasma treatment is shown in Fig. 9 as a function of the treatment time. With increasing treatment time the WVTR value strongly decreases for 2, 5 and $8 \mathrm{~min}$ down to $\sim 3 \times 10^{-3} \mathrm{~g} / \mathrm{m}^{2}$. day. For longer

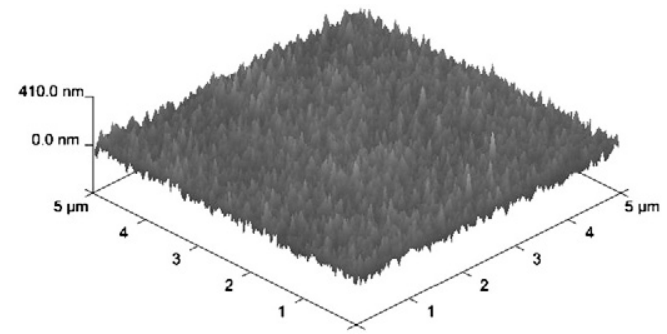

(b)

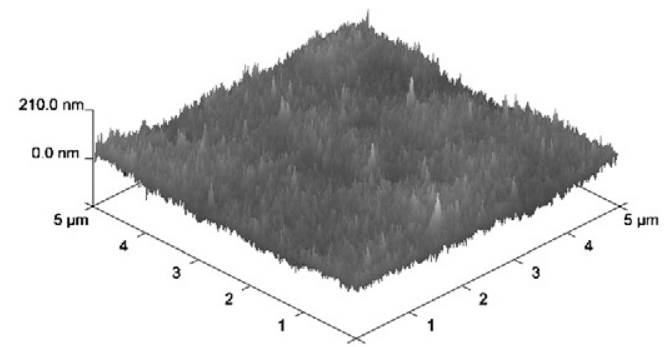

(d)

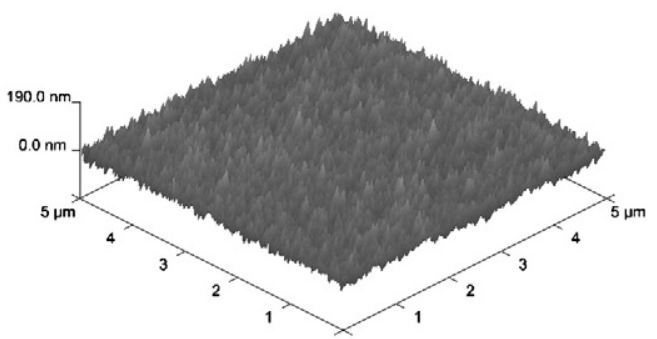

(f)

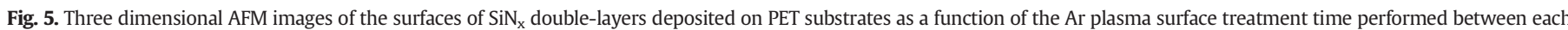
single-layer deposition: (a) Not treated, (b) 2 min Ar-treated, (c) 5 min Ar-treated, (d) 8 min Ar-treated, (e) 10 min Ar-treated and (f) 15 min Ar-treated. 


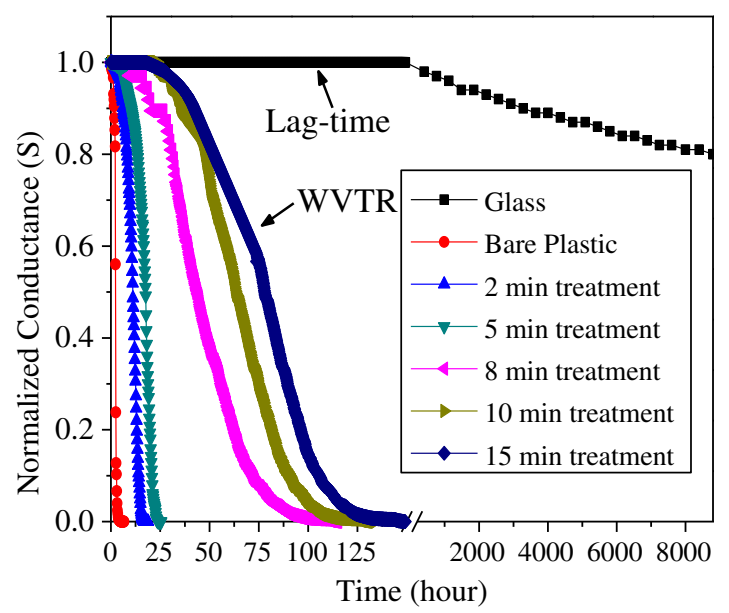

Fig. 7. Normalized conductance of Ca sensors deposited on bare PET as well as on barrier coated PET substrates versus time for two $50 \mathrm{~nm}$ thick $\mathrm{SiN}_{\mathrm{x}}$ single-layers separated by $\mathrm{Ar}$ plasma surface treatment for different plasma exposure times. Normalized conductance of Ca deposited on glass is used as reference. The conductance of glass-glass sample is reduced only $20 \%$ after 8000 h of operation.

treatment times almost no variation on the WVTR value is observed. This is probably due to the fact that during the first few minutes of treatment, the impinging $\mathrm{Ar}^{+}$ions are inducing atomic relocations on the surface of the $\mathrm{SiN}_{\mathrm{x}}$ layer uniquely and $8 \mathrm{~min}$ is the optimal time to get atomic rearrangements up to few $\mathrm{nm}$ in depth inside the film. Once the densification of the single-layer to a few $\mathrm{nm}$ in depth has been completed, the whole interface is stabilized and there is almost no effect on WVTR values for higher treatment times. Obviously if the mean energy of the ions was higher, the necessary time would be less than $8 \mathrm{~min}$. We observe a slight decrease of the roughness and a pronounced decrease of the WVTR versus Ar-treatment time. The reason could be that a small compactness of the interface layer may have a drastic effect on the diffusion of the permeate through the whole barrier structure.

\section{Conclusion}

With the HW-CVD technique, based on silane and ammonia gaseous mixtures diluted in hydrogen at $T_{\text {sub }}=100{ }^{\circ} \mathrm{C}$ and after an optimization taking into account the different growth parameters, we have deposited device quality silicon nitride thin films which can be used as barrier layers for flexible organic photovoltaic cells. Using the electrical calcium degradation test, we have demonstrated the decrease of WVTR

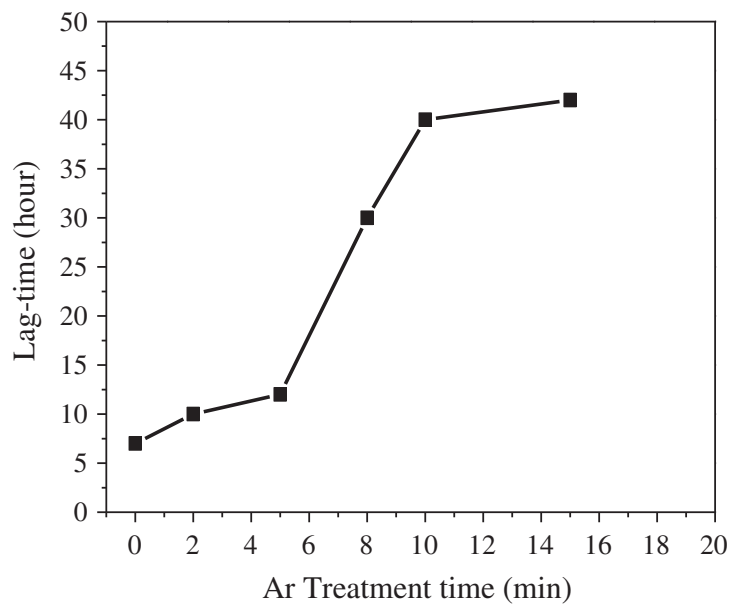

Fig. 8. Evolution of the "lag-time" versus the Ar plasma treatment time of the $\mathrm{SiN}_{\mathrm{x}}$ films as a function of the Ar plasma exposure time.

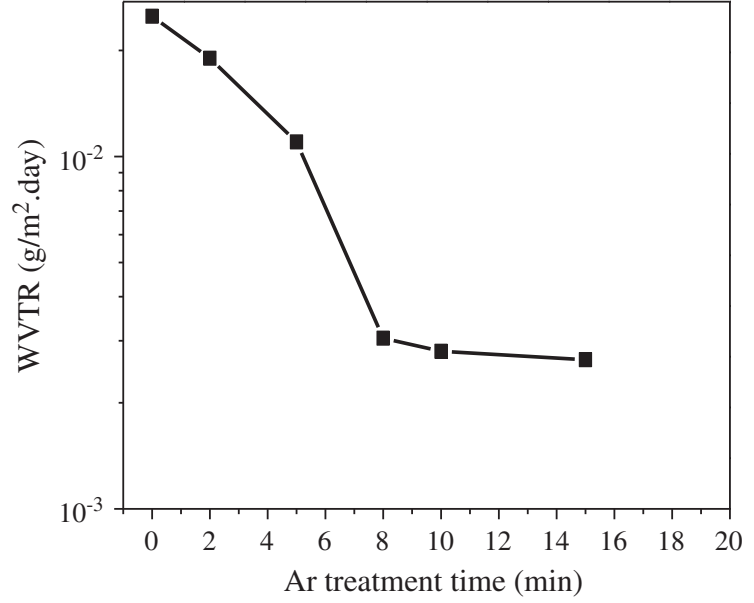

Fig. 9. Evolution of WVTR values versus the Ar plasma treatment time of the $\operatorname{SiN}_{\mathrm{x}}$ films as a function of the Ar plasma exposure time.

value for $\mathrm{SiN}_{\mathrm{x}}$ covered PET samples compared to bare PET substrates. Furthermore, we have shown that instead of using an actual physical (generally organic) interlayer, an Ar plasma surface treatment between each successive $\mathrm{SiN}_{\mathrm{x}}$ single-layer can reduce drastically the WVTR value. Using an $8 \mathrm{~min}$ Ar treatment for double-layer (50 $\mathrm{nm}+\mathrm{Ar}$ treatment $+50 \mathrm{~nm}$ ) we have achieved a WVTR value down to $\sim 3 \times 10^{-3} \mathrm{~g} / \mathrm{m}^{2}$. day, which for thicker layers (number of layer $>2$ ) will expectedly give a longer shelf lifetime of organic photovoltaic cells. Therefore the next step in this research concerns the increase of the number of the multilayers i.e. the total thickness to reduce the permeation rate even further.

\section{Acknowledgments}

The authors would like to thank Cyril Jadaud for his help in the mechanical design, J. C. Vanel for his help in electrical characterizations, and Jacqueline Tran and Hassina D. Habak for their help in the optical characterization techniques used in this study. The first author (S.M.) acknowledges the financial support from Direction des Relations Extérieures, Ecole Polytechnique for his thesis. This study has been supported by PICS (French-Portuguese no: 5336) project.

\section{References}

[1] W. Prins, J.J. Hermans, J. Phys. Chem. 63 (1959) 716.

[2] T.A. Beu, P.-V. Mercea, Mater. Chem. Phys. 26 (1990) 309.

[3] M.S. Weaver, L.A. Michalski, K. Rajan, M.A. Rothman, J.A. Silvernail, J.J. Brown, P.E. Burrows, G.L. Graff, M.E. Gross, P.M. Martin, M. Hall, E. Mast, C. Bonham, W. Bennett, M. Zumhoff, Appl. Phys. Lett. 81 (2002) 2929.

[4] J. Fahlteich, M. Fahland, W. Schonberger, N. Schiller, Thin Solid Films 517 (2009) 3075-3080.

[5] P.F. Carcia, R.S. McLean, M.H. Reilly, M.D. Groner, S.M. George, Appl. Phys. Lett. 89 (2006) 031915.

[6] J. Meyer, D. Schneidenbach, T. Winkler, S. Hamwi, T. Weimann, P. Hinze, S. Ammermann, H.H. Johannes, T. Riedl, W. Kowalsky, Appl. Phys. Lett. 94 (2009) 233305.

[7] D. Spee, K. van der Werf, J. Rath, R. Schropp, Phys. Status Solidi RRL 6 (2012) 151-153.

[8] J. Greener, K.C. Ng, K.M. Vaeth, T.M. Smith, J. Appl. Polym. Sci. 106 (2007) 3534

[9] T.W. Kim, M. Yan, A.G. Erlat, P.A. McConnelee, M. Pellow, J. Deluca, T.P. Feist, A.R. Dugal, M. Schaepkens, J. Vac. Sci. Technol. A 23 (4) (2005) 971.

[10] V. Verlaan, R. Bakker, C.H.M. van der Werf, Z.S. Houweling, Y. Mai, J.K. Rath, R.E.I. Schropp, Surf. Coat. Technol. 201 (2007) 9285.

[11] H. Nakayama, M. Ito, Thin Solid Films 519 (2011) 4483-4486.

[12] P. Alpuim, L.M. Gonçalves, E.S. Marins, T.M.R. Viseu, S. Ferdov, J.E. Bourée, Thin Solid Films 517 (2009) 3503-3506.

[13] Y. Ogawa, K. Ohdaira, T. Oyaidu, H. Matsumura, Thin Solid Films 516 (2008) 611-614.

[14] J. Ubrig, S. Martin, S. Cros, J.E. Bourée, J. Phys. Conf. Ser. 100 (2008) 082030.

[15] J.A. Hauch, P. Schilinsky, S.A. Choulis, S. Rajoelson, C.J. Brabec, Appl. Phys. Lett. 93 (2008) 103306.

[16] S. Cros, R. de Bettignies, S. Berson, S. Bailly, P. Maisse, N. Lemaitre, S. Guillerez, Sol. Energy Mater. Sol. Cells 95 (2011) S65-S69. 
[17] G.L. Graff, R.E. Williford, P.E. Burrows, J. Appl. Phys. 96 (2004) 1840.

[18] S. Schubert, H. Klumbies, L. Muller-Meskamp, K. Leo, Rev. Sci. Instrum. 82 (2011) 094101.

[19] R. Paetzold, A. Winnacker, D. Henseler, V. Cesari, K. Heuser, Rev. Sci. Instrum. 74 (2003) 5147.

[20] M.O. Reese, A.A. Dameron, M.D. Kempe, Rev. Sci. Instrum. 82 (2011) 085101.

[21] H.C. Cheng, in: C.Y. Chang, S.M. Sze (Eds.), ULSI Technology, International editions, McGraw-Hill, Singapore, 1996, p. 205, (Chapter 5).

[22] Alain C. Diebold, Handbook of Silicon Semiconductor Metrology, Marcel Dekker Inc., 2001. 758.
[23] J.W. Klaus, A.W. Ott, A.C. Dillon, S.M. George, Surf. Sci. 418 (1998) L14L19.

[24] D.S. Katzer, D.J. Meyer, D.F. Storm, J.A. Mittereder, V.M. Bermudez, S.F. Cheng, G.G Jernigan, S.C. Binari, J. Vac. Sci. Technol. B 30 (2012) 02B129.

[25] S.M. Sze, K.K. Ng, Physics of Semiconductor Devices, Third edition Wiley-Interscience 2007. 791.

[26] J. Cuomo, S.M. Rossnagel, H.R. Kaufman, Handbook of Ion Beam Processing Technology, Noyes Publications, Park Ridge, N. J., 1989. 180.

[27] R. Vernhes, A. Amassian, J.E. Klemberg-Sapieha, L. Martinu, J. Appl. Phys. 99 (2006) 114315 